\title{
Reasons for coming to hospital after treatment for community-acquired pneumonia on an ambulatory basis
}

\author{
Mohammedreza Shariatzadeh MD, Thomas J Marrie MD
}

M Shariatzadeh, TJ Marrie. Reasons for coming to hospital after treatment for community-acquired pneumonia on an ambulatory basis. Can Respir J 2006;13(3):139-143.

BACKGROUND: Most patients with community-acquired pneumonia (CAP) are treated on an ambulatory basis.

OBJECTIVE: To evaluate the reasons for presentation to hospital after treatment for CAP on an ambulatory basis.

METHODS: The study, conducted in five hospitals in the Capital Health Region (Edmonton, Alberta), enrolled adult patients aged 17 years or older who presented with a history of having been diagnosed and treated for pneumonia within the previous month. A current diagnosis of pneumonia was based on two or more symptoms or signs of CAP, plus radiographic evidence of pneumonia.

RESULTS: Seventy-five (77.3\%) of the 97 patients who met the inclusion criteria had CAP, and $22(22.7 \%)$ patients presented with a noninfectious illness. Of the patients with CAP, 25 (33.3\%) met the study criteria for worsening of a comorbid illness, 23 (30.7\%) had clinical failure, 16 (21.3\%) had microbiological failure, six $(8.0 \%)$ were noncompliant, four $(5.3 \%)$ had failure of expectations and one (1.3\%) had adverse effects of antimicrobial therapy.

CONCLUSIONS: Underlying diseases, exacerbations of comorbidities and complications of CAP, as well as confounders such as unusual infections and noninfectious conditions that mimic CAP, are all reasons for presenting to hospital after treatment for CAP in an ambulatory setting.

Key Words: Community-acquired pneumonia; Reasons for consulting hospital

Tnatient management of community-acquired pneumonia 1 (CAP) is more costly than treatment on an ambulatory basis. In the United States, CAP is responsible for 4.5 million office visits and more than one million hospitalizations annually $(1,2)$. Many patients with CAP are treated on an ambulatory basis following an assessment in their physician's office. This group of patients has not been subjected to the same degree of study as patients who are admitted to hospital for treatment of CAP (3-5). The present study was designed to evaluate a subset of patients who presented to emergency departments following diagnosis and treatment of CAP on an ambulatory basis.

\section{MATERIALS AND METHODS}

The present study was conducted in five hospitals in the Capital Health Region (Edmonton, Alberta), from December 2002 to April 2004. The Research Ethics Board at the University of Alberta approved the study.

\section{Raisons des consultations en clinique hospitalière de soins ambulatoires après un traitement pour pneumonie extra-hospitalière}

HISTORIQUE : La plupart des patients qui contractent une pneumonie extra-hospitalière $(\mathrm{PEH})$ sont traités en clinique hospitalière de soins ambulatoires.

OBJECTIF : Expliquer les raisons de consulter en clinique de soins ambulatoires après un traitement pour $\mathrm{PEH}$.

MÉTHODES : L'étude menée dans cinq hôpitaux de la région sanitaire de la capitale (Edmonton [Alberta]) a regroupé des patients adultes de 17 ans et plus qui avaient reçu un diagnostic de pneumonie et le traitement nécessaire au cours du mois précédent. Le diagnostic de pneumonie évolutive se fondait sur la présence de deux symptômes ou signes de PEH, preuves radiologiques à l'appui.

RÉSULTATS : Soixante-quinze $(77,3 \%)$ patients sur les 97 qui répondaient aux critères d'admissibilité souffraient effectivement de $\mathrm{PEH}$ et $22(22,7 \%)$ présentaient un état non infectieux. Parmi les patients souffrant de PEH, 25 (33,3 \%) répondaient aux critères d'aggravation d'une comorbidité établis aux fins de l'étude, 23 (30,7 \%) présentaient un échec thérapeutique clinique, 16 (21,3\%) présentaient un échec thérapeutique microbiologique, six $(8,0 \%)$, un problème de non-observance thérapeutique, quatre $(5,3 \%)$, un échec sur le plan des résultats attendus et un seul $(1,3 \%)$ a mal réagi à l'antibiothérapie.

CONCLUSIONS : Une maladie sous-jacente, l'exacerbation de certaines comorbidités, les complications de la PEH, de même que certains facteurs de confusion tels que la présence d'infections inhabituelles et de maladies non infectieuses prises à tort pour une $\mathrm{PEH}$ font partie des raisons pour lesquelles des sujets se sont présentés à une clinique hospitalière de soins ambulatoires après un traitement pour $\mathrm{PEH}$.

Participants were adults aged 17 years or older who presented with a history of having been diagnosed (with or without chest radiography) with and treated with antibiotics for pneumonia, either in their physician's office or in emergency departments within the previous month. Patients were enrolled only during daytime hours because research nurses were not present for $24 \mathrm{~h}$ a day in participating emergency departments.

A current diagnosis of pneumonia was based on two or more symptoms or signs of CAP, plus radiographic evidence of pneumonia, as interpreted by an emergency room physician or an internal medicine consultant. Symptoms and signs of CAP included productive or nonproductive cough, pleuritic chest pain, shortness of breath, a temperature of $38^{\circ} \mathrm{C}$ or higher, and crackles on auscultation. Data collected at the time of enrollment included the following: demographic information; previous history of admission to hospital, drug use and antibiotic therapy; type, dose and reason for antibiotic prescriptions; vaccination history; symptoms;

Department of Medicine, University of Alberta, Edmonton, Alberta

Correspondence: Dr Thomas J Marrie, Faculty of Medicine and Dentistry, 2J2.01 Walter C Mackenzie Health Sciences Centre, 8440 - 112 Street, Edmonton, Alberta T6G 2R7. Telephone 780-492-9728, fax 780-492-7303, e-mail tom.marrie@ualberta.ca 
TABLE 1

Characteristics of the study population $(n=97)$

\begin{tabular}{lc}
\hline Characteristic & $\mathbf{n}(\%)$ \\
\hline Women & $47(47.9)$ \\
Smokers & $22(22.7)$ \\
Ex-smokers & $37(38.1)$ \\
Substance abuse & $12(12.4)$ \\
Alcohol abuse & $6(6.2)$ \\
History of tuberculosis & $3(3.1)$ \\
One antibiotic given before admission (within past week) & $79(81.4)$ \\
Two antibiotics given before admission (within past week) & $8(8.2)$ \\
Three antibiotics given before admission (within past week) & $2(2.1)$ \\
Chronic obstructive pulmonary disease & $33(34.0)$ \\
Ischemic heart disease & $23(23.7)$ \\
Dementia & $19(19.6)$ \\
Congestive heart failure & $14(14.4)$ \\
Asthma & $13(13.4)$ \\
Cancer & $11(11.3)$ \\
Remote stroke & $10(10.3)$ \\
Renal disease & $8(8.2)$ \\
Depression & $8(8.2)$ \\
HIV-positive & $5(5.2)$ \\
Seizures, IBD, diabetes mellitus or liver disease (one each) & $4(4.1)$
\end{tabular}

IBD Inflammatory bowel disease

and laboratory findings and cultures. A symptom severity score at the time of the current presentation was calculated. The severity scale for each of five symptoms (cough, sputum production, chest pain, fatigue and dyspnea) was noted on a six-point scale ranging from zero (no symptoms) to five (very severe symptoms), as previously described (4).

\section{Definitions}

Reasons for failure of therapy (listed below) were developed before the start of the study based on a review of the literature and the experience of the investigators.

Microbiological failure: A positive blood culture or positive sputum and/or pleural fluid culture for a respiratory pathogen, irrespective of the susceptibility status of the microorganism, after $48 \mathrm{~h}$ or more of antibiotic therapy; the presence of Pneumocystis carinii on a smear of sputum or bronchoalveolar lavage.

Clinical failure: Any one of the following after $48 \mathrm{~h}$ or longer of therapy:

- An increase of $25 \%$ or more in the extent of the pulmonary infiltrate on chest radiograph;

- Hypotension as defined as a systolic blood pressure of less than $90 \mathrm{mmHg}$ or a drop of $30 \mathrm{mmHg}$ or greater from a previously known blood pressure;

- A temperature of $38.5^{\circ} \mathrm{C}$ or higher; or

- Oxygen saturation of $90 \%$ or less, or a partial pressure of oxygen of $60 \mathrm{mmHg}$ or less while breathing room air (for patients who have not been receiving home oxygen).

Noncompliance: Missed one or more days of antibiotic therapy (as self-reported) in the interval between starting the antibiotics and presentation to the emergency room.

Adverse effects: Any nausea, vomiting, diarrhea, anaphylaxis or skin rash that resulted in the visit and was thought by the
TABLE 2

Antibiotics prescribed to subjects within one week before enrollment in the study $(n=89)$

\begin{tabular}{lc}
\hline Antibiotic & $\mathbf{n}(\%)$ \\
\hline Levofloxacin & $32(36.0)$ \\
Clarithromycin & $26(29.2)$ \\
Azithromycin & $12(13.5)$ \\
Cefuroxime & $10(11.2)$ \\
Amoxicillin & $4(4.5)$ \\
Erythromycin & $4(4.5)$ \\
Ciprofloxacin & $4(4.5)$ \\
Cefazolin & $2(2.2)$ \\
Ceftriaxone & $1(1.1)$ \\
Cefaclor & $1(1.1)$ \\
Moxifloxacin & $1(1.1)$ \\
Clindamycin & $1(1.1)$ \\
Telithromycin & $1(1.1)$ \\
Trimethoprim-sulfamethoxazole & $1(1.1)$ \\
Doxycycline & $1(1.1)$
\end{tabular}

physician to be due to the antibiotic that was prescribed to treat the pneumonia.

Worsening of a comorbid illness: Examples included diabetes out of control, an increase in the frequency and/or severity of angina, and exacerbation of asthma or chronic obstructive pulmonary disease (COPD).

Failure of expectations: A compliant patient who was still symptomatic but presented within $48 \mathrm{~h}$ of starting antibiotics and was afebrile (temperature of $37.5^{\circ} \mathrm{C}$ or less), and had a pulse rate of less than 100 beats/min and a respiratory rate of less than 24 breaths/min.

Noninfectious illness: Included noninfectious diseases that mimicked pneumonia such as cancer of the lung or metastasis to the lung, inflammatory lung disease, congestive heart failure (CHF) and COPD. All patients with cancer had histological confirmation of the diagnosis. Diagnoses of CHF and COPD were defined by the attending physicians.

\section{Statistical analysis}

For analysis of data, SPSS version 12.0 (SPSS Inc, USA) was used. Descriptive statistics and the differences between means and proportions were tested by using Student's $t$ test, and the $\chi^{2}$ test or Fisher's exact test.

\section{RESULTS}

Three patients were excluded from the analysis because they did not meet study criteria. The characteristics of the remaining 97 patients are shown in Table 1 . There were 50 (51.5\%) men and the mean age of the study population was $62.7 \pm 18.4$ years. Eighty $(82.5 \%)$ patients were admitted to hospital for treatment. Eighty-nine (91.8\%) patients had received antibiotics within one week before enrollment (Table 2).

The final diagnoses in patients with a chest radiograph interpreted as pneumonia or with no chest radiography during their first visit are shown in Table 3.

Seventy-five $(77.3 \%)$ patients had CAP and $22(22.7 \%)$ patients had a noninfectious illness. No differences were found in the time from the onset of therapy to the second visit between CAP patients and those who were subsequently found not to 
TABLE 3

Comparisons of final diagnoses in patients with chest radiography interpreted as pneumonia or no chest radiography at the time of their first visit

\begin{tabular}{lcc}
\hline Final diagnosis & $\begin{array}{c}\text { Chest radiograph } \\
\text { interpreted as pneumonia } \\
\text { during first visit }(\mathbf{n = 3 9 )}\end{array}$ & $\begin{array}{c}\text { Chest radiograph } \\
\text { not performed } \\
(\mathbf{n = 5 8 )}\end{array}$ \\
\hline CAP, n (\%) & $28 / 39(71.8)$ & $47 / 58(81.0)$ \\
Noninfectious diagnosis, $\mathrm{n}(\%)$ & $11 / 39(28.2)$ & $11 / 58(19.0)$ \\
Cancer & 5 & 3 \\
CHF & 2 & 5 \\
CHF and COPD & 1 & 1 \\
Pulmonary fibrosis & 2 & - \\
BOOP & 1 & 1 \\
Asthma and bronchitis & - & 1 \\
\hline
\end{tabular}

BOOP Bronchiolitis obliterans with organizing pneumonia; CAP Communityacquired pneumonia; CHF Congestive heart failure; COPD Chronic obstructive pulmonary disease

have CAP $(8.1 \pm 6.9$ versus $8.0 \pm 7.2$ days, respectively; $\mathrm{P}=0.912)$. Of the 75 patients with CAP, $25(33.3 \%)$ met the criteria for worsening of a comorbid illness, $23(30.7 \%)$ had clinical failure, $16(21.3 \%)$ had microbiological failure, six $(8.0 \%)$ were noncompliant, four $(5.3 \%)$ met the criteria for failure of expectations and one $(1.3 \%)$ had an adverse reaction to cefaclor, manifested by a rash (Table 4$)$.

The antibiotics prescribed to the 16 patients with microbiological failure were as follows: clarithromycin and levofloxacin for four patients each; azithromycin for three patients; cefuroxime for two patients; and clindamycin, cefaclor and doxycycline for one patient each. The antibiotics prescribed for the 23 patients with clinical failure were as follows: clarithromycin for eight patients; azithromycin for five patients; levofloxacin for four patients; ciprofloxacin and cefuroxime for three patients each; and erythromycin and telithromycin for one patient each. An HIV-infected patient who later proved to have $P$ carinii pneumonia (PCP) had received three antibiotics (levofloxacin, cefuroxime and clarithromycin) in succession.

Twenty-two $(88.0 \%)$ patients with worsening of comorbid illness had COPD, two of them accompanied by CHF; three patients had asthma. Seventeen $(73.9 \%)$ of the clinical failure cases had at least one comorbidity and 14 (60.9\%) had at least one complication. Overall, 21 (91.3\%) patients with clinical failure had underlying illnesses or complications at the time of their second visit; $43.5 \%(n=10)$ had involvement of more than one lobe and $30.4 \%(n=7)$ had bilateral pulmonary infection. Of four cases with failure of expectations, three patients had underlying illnesses, and another one had bilateral pulmonary infiltrates. Table 4 shows the reasons for failure of ambulatory therapy. Three patients with PCP, all of whom were positive for HIV, had viral loads of more than 300,000 copies/mL HIV RNA, and $\mathrm{CD}_{4}$ counts of less than 200 cells/ $\mu \mathrm{L}$. Another patient had tuberculosis with pleural effusion, discitis and vertebral body erosions of T8 and T9.

$\mathrm{CHF}(\mathrm{n}=9)$ and malignancy involving the lung $(\mathrm{n}=8)$ were two main noninfectious diseases that mimicked CAP. Eight patients had cancer of the lung, including metastasis to the lung $(n=2)$; in seven patients, this was a new diagnosis. One patient with known bronchoalveolar cell carcinoma had exacerbations of signs and symptoms, which was misinterpreted as pneumonia. Two patients had bronchiolitis obliterans with organizing pneumonia (BOOP). One patient had pulmonary fibrosis
TABLE 4

\begin{tabular}{|c|c|}
\hline & $\mathrm{n}(\%)$ \\
\hline Patients with community-acquired pneumonia & 75 (77.3) \\
\hline Worsening of comorbid illness & 25/75 (33.3) \\
\hline Clinical failure & $23 / 75(30.7)$ \\
\hline Microbiological failure & $16 / 75(21.3)$ \\
\hline Noncompliance & $6 / 75(8.0)$ \\
\hline Failure of expectations & $4 / 75(5.3)$ \\
\hline Adverse effects & $1 / 75(1.3)$ \\
\hline Patients with no pneumonia & $22(22.7)$ \\
\hline $\mathrm{CHF}$ & $7 / 22(31.8)$ \\
\hline $\mathrm{CHF}$ and COPD & $2 / 22(9.1)$ \\
\hline Cancer of the lung or metastasis to lung & $8 / 22(36.4)$ \\
\hline BOOP & $2 / 22(9.1)$ \\
\hline Pulmonary fibrosis & $2 / 22(9.1)$ \\
\hline Asthma and bronchitis & $1 / 22(4.5)$ \\
\hline
\end{tabular}

BOOP Bronchiolitis obliterans with organizing pneumonia; CHF Congestive heart failure; COPD Chronic obstructive pulmonary disease

secondary to scleroderma and, in another patient, this was secondary to radiation therapy.

There were no significant differences in laboratory findings between those with CAP and those who were subsequently shown not to have CAP.

Seventeen microorganisms were recovered from the sputum specimens of 15 patients (two patients had two organisms each) (Table 5). Fourteen of the 16 patients who had had organisms isolated from sputum or pleural fluid had received antibiotics within one week before admission.

Dyspnea in both CAP patients and in non-CAP patients had the highest symptom severity scores $(3.97 \pm 1.29$ and $3.73 \pm 1.20$, respectively; $\mathrm{P}=$ not significant), and chest pain had the lowest score $(1.84 \pm 1.79$ and $0.64 \pm 0.95$, respectively; $\mathrm{P}<0.001)$. Only the severity of chest pain and total pneumonia symptom severity score were significantly different. The mean length of stay for 61 patients hospitalized with CAP was $14.2 \pm 20.9$ days and, for non-CAP patients, it was $12.0 \pm 10.4$ days $(\mathrm{P}=0.653)$.

Four patients died, all of whom were men older than 65 years of age. Two of these patients had cancer of the lung and COPD; another patient had esophageal cancer, COPD and ischemic heart disease. The fourth patient had diabetes mellitus and chronic renal failure.

\section{DISCUSSION}

In the present study, the common reasons for treatment failure in patients with CAP were worsening of comorbid illness, clinical failure and microbiological failure. Noncompliance $(n=6)$, failure of expectations $(n=4)$ and adverse effects $(n=1)$ were the remaining reasons. In a study of patients hospitalized after initial outpatient treatment for CAP, Minogue et al (6) noted that of 944 patients initially treated as outpatients, $71(7.5 \%)$ were hospitalized within the next month. Forty of these were hospitalized for a CAP-related reason: 33 for worsening symptoms or signs of CAP and seven for an adverse reaction to an antibiotic prescribed for CAP.

The majority of patients with clinical failure and failure of expectations had an underlying illness or developed a 


\begin{tabular}{llc}
$\begin{array}{l}\text { TABLE 5 } \\
\text { Microbiological diagnoses among ambulatory community- } \\
\text { acquired pneumonia patients at the time of the second } \\
\text { visit (n=97) }\end{array}$ & $\mathbf{n}(\%)$ \\
\hline Test & Performed & $48(49.5)$ \\
\hline Sputum culture & Positive & $12(25)^{*}$ \\
Sputum culture result & Haemophilus influenzae & 4 \\
& Staphylococcus aureus & 3 \\
& Streptococcus pneumoniae & 3 \\
& Moraxella catarrhalis & 1 \\
& Klebsiella pneumoniae & 1 \\
& Proteus mirabilis & 1 \\
Sputum smear result & Mycobacterium tuberculosis & 1 \\
Pleural fluid culture & Pneumocystis carinii & 3 \\
Blood culture & Streptococcus anginosus & 1 \\
& Performed & $62(63.9)$ \\
& Positive & $1(1.6)$ \\
& S aureus & 1 \\
\hline
\end{tabular}

*In two samples, two organisms were recovered in combination, $\mathrm{H}$ influenzae with $\mathrm{M}$ catarrhalis, and $\mathrm{H}$ influenzae with $\mathrm{S}$ pneumoniae

complication. In a study of 533 nonseverely immunosuppressed adult patients who were hospitalized for CAP on the basis of conventional admission criteria, Rosón et al (7) noted that CAP patients in risk classes I to III were hospitalized for reasons including comorbidities, respiratory failure and complications such as clinically significant pleural effusion.

One of the important findings of our study was the three cases of PCP and the one case of tuberculosis, reminding us that these infections should never be forgotten in the differential diagnosis of patients with CAP. While the frequency of PCP as a presentation of HIV infection has declined due to the advent of highly active antiretroviral therapy, some patients do not know that they have been infected with this virus and, therefore, present late in the course of the infection with PCP, as exemplified by the present study and other studies $(8,9)$.

In a one-year study of CAP in France, Lévy et al (10) noted that Mycobacterium tuberculosis was responsible for $10 \%$ $(n=12)$ of cases. In a study at a community teaching hospital in Ohio (USA), Counsell et al (11) found that pulmonary tuberculosis was not suspected in 13 of $31(42 \%)$ patients at the time of the initial evaluation. Pneumonia was the admitting diagnosis in the majority of these patients. Elderly patients with pulmonary tuberculosis were significantly less likely to be initially suspected of having the disease than younger patients. Among 11 patients younger than 65 years of age, only one was not initially suspected of having the disease, whereas among 20 patients aged 65 years or older, 12 (60\%) were not suspected of having the disease.

Sputum culture was positive for Staphylococcus aureus in three patients. In a prospective study of CAP of bacterial etiology in adults in Spain (12), only two of 228 cases had S aureus. In another prospective outpatient study of 170 patients with CAP in Switzerland, none of the 107 etiological agents that were identified in 92 patients were $S$ aureus (13). In a study of etiological agents in hospitalized adult patients with CAP in the United Kingdom (14), only four of 199 patients who were admitted to hospital were diagnosed as having $S$ aureus. These data suggest that patients with CAP who present following initial treatment in an ambulatory setting are more likely to have $S$ aureus as a pathogen than are those who are admitted to hospital without prior treatment.

In our study, $\mathrm{CHF}, \mathrm{CHF}$ plus $\mathrm{COPD}$, cancer of the lung, BOOP and pulmonary fibrosis were the main noninfectious diseases misdiagnosed as CAP. Alves dos Santos et al (15) carried out a study of noninfectious and unusual infectious mimics of CAP in 180 patients who were hospitalized with suspicion of CAP. Sixteen patients had a diagnosis other than CAP; one-half of them were noninfectious in origin. In two patients, pulmonary embolism with pulmonary infarction was diagnosed. Cryptogenic organizing pneumonia, bronchocentric granulomatosis, Wegener's granulomatosis, hypersensitivity pneumonitis, acute leukemia with pulmonary infiltration and pulmonary metastasis of gastric carcinoma occurred in one patient each.

Because of changes in lung parenchyma in COPD, CHF can mimic pneumonia in these patients.

Neoplastic processes may masquerade as pneumonia because of the clinical presentation and the appearance on chest radiograph. The differential diagnosis is made more challenging by the fact that chronically ill or elderly patients may have pneumonia without fever (16). Coughing or a change in the character of a chronic cough is the most common presenting manifestation of lung cancer. Dyspnea is a presenting symptom of lung cancer in as many as $60 \%$ of symptomatic patients, particularly if there is a large or centrally obstructing lesion (16). Fever is rarely a cardinal manifestation of lung cancer. Most neoplasms involving the lung appear on chest radiograph as nodular densities, or they present as an infiltrative process that may be difficult to distinguish radiographically from pneumonia (16).

BOOP continues to be a pneumonia mimic $(17,18)$. Although most cases of BOOP are idiopathic, there are several known causes (19). The typical chest radiograph shows bilateral, patchy (alveolar) infiltrates. Generally, the infiltrates gradually enlarge from their original site, or new infiltrates appear as the clinical course progresses; however, migratory or mobile pulmonary infiltrates have been reported $(20,21)$.

Collagen vascular diseases can also present as pneumonia $(22,23)$. Systemic sclerosis, diagnosed in one of our patients, is a systemic fibrotic disease of unknown etiology with different kinds of pulmonary complications, including interstitial pneumonitis, pleuritis and aspiration pneumonia.

One of the most interesting findings of our study was the low rate of antimicrobial resistance among the organisms isolated. National surveillance data from the United States suggest that $35 \%$ of all strains of pneumococci are resistant to penicillin (24); moreover, in vitro resistance to macrolides is $25.9 \%$, resistance to clindamycin is $8.8 \%$, resistance to tetracycline is $16.4 \%$ and resistance to trimethoprim-sulfamethoxazole is $30.3 \%$ (25). Respiratory fluoroquinolones have had a negligible increase in resistance rates in the United States, although in Canada, there have been increases that correlate with increased ciprofloxacin use (26). Comparative studies suggest that macrolides and fluoroquinolones are both appropriate therapy for outpatients with CAP (27).

One of the weaknesses of our study is that we used a convenience sample; therefore, we cannot provide a rate for the failure of pneumonia treated on an ambulatory basis. Another weakness is that we accepted a physician diagnosis of pneumonia on the first visit. However, that is what happens in the real world of everyday practice. 


\section{CONCLUSIONS}

We conclude that the reasons for presentation to hospital after treatment for CAP on an ambulatory basis are diverse, and include conditions such as collagen vascular diseases that present as pneumonia (pneumonia mimics), misdiagnosis of pneumonia, clinical failure, failure of patient expectations and microbiological failure. Incomplete microbiological evaluation prevented us from determining the true role of microbiological failure in this patient population.

ACKNOWLEDGEMENTS: This study was funded by a grant from Janssen-Ortho Canada Inc. We gratefully acknowledge the following research nurses: Carol Mangan RN, Virginia Willis RN, Lynne Korobanik RN, Cynthia Proskow RN and Nancy Baker RN. The staff of the EPICORE Centre carried out data management for the project and Jane Huang helped with data analysis. Thanks to Sheila Taddeo for editing the manuscript.

\section{REFERENCES}

1. Niederman MS, McCombs JS, Unger AN, Kumar A, Popovian R. The cost of treating community-acquired pneumonia. Clin Ther 1998;20:820-37.

2. Wennberg JE, McPherson K, Caper P. Will payment based on diagnosis-related groups control hospital costs? N Engl J Med 1984;311:295-300.

3. Bartlett JG, Dowell SF, Mandell LA, File TM Jr, Musher DM, Fine MJ. Practice guidelines for the management of community-acquired pneumonia in adults. Infectious Diseases Society of America. Clin Infect Dis 2000;31:347-82.

4. Marrie TJ, Beecroft MD, Herman-Gnjidic Z. Resolution of symptoms in patients with community-acquired pneumonia treated on an ambulatory basis. J Infect 2004;49:302-9.

5. Malcolm C, Marrie TJ. Antibiotic therapy for ambulatory patients with community-acquired pneumonia in an emergency department setting. Arch Intern Med 2003;163:797-802.

6. Minogue MF, Coley CM, Fine MJ, Marrie TJ, Kapoor WN, Singer DE. Patients hospitalized after initial outpatient treatment for community-acquired pneumonia. Ann Emerg Med 1998;31:376-80.

7. Rosón B, Carratala J, Dorca J, Casanova A, Manresa F, Gudiol F. Etiology, reasons for hospitalization, risk classes, and outcomes of community-acquired pneumonia in patients hospitalized on the basis of conventional admission criteria. Clin Infect Dis 2001;33:158-65.

8. Jedlovsky V, Fleischman JK. Pneumocystis carinii pneumonia as the first presentation of HIV infection in patients older than fifty. AIDS Patient Care STDS 2000;14:247-9.

9. Morris A, Lundgren JD, Masur H, et al. Current epidemiology of Pneumocystis pneumonia. Emerg Infect Dis 2004;10:1713-20
10. Lévy M, Dromer F, Brion N, Leturdu F, Carbon C. Communityacquired pneumonia. Importance of initial noninvasive bacteriologic and radiographic investigations. Chest 1988;93:43-8.

11. Counsell SR, Tan JS, Dittus RS. Unsuspected pulmonary tuberculosis in a community teaching hospital. Arch Intern Med 1989;149:1274-8.

12. Sopena N, Sabria M, Pedro-Botet ML, et al. Prospective study of community-acquired pneumonia of bacterial etiology in adults. Eur J Clin Microbiol Infect Dis 1999;18:852-8.

13. Bochud PY, Moser F, Erard P, et al. Community-acquired pneumonia. A prospective outpatient study. Medicine (Baltimore) 2001;80:75-87.

14. Lim WS, Macfarlane JT, Boswell TC, et al. Study of community acquired pneumonia aetiology (SCAPA) in adults admitted to hospital: Implications for management guidelines. Thorax 2001;56:296-301.

15. Alves dos Santos JW, Torres A, Michel GT, et al. Non-infectious and unusual infectious mimics of community-acquired pneumonia. Respir Med 2004;98:488-94.

16. Casey KR. Neoplastic mimics of pneumonia. Semin Respir Infect 1995; 10:131-42.

17. Chang J, Han J, Kim DW, et al. Bronchiolitis obliterans organizing pneumonia: Clinicopathologic review of a series of 45 Korean patients including rapidly progressive form. J Korean Med Sci 2002;17:179-86.

18. Song J, Gorgan L, Corkey R, Kwa SL. An unusual case of bronchiolitis obliterans organizing pneumonia concomitant with bronchioloalveolar carcinoma. Respiration 2004;71:95-7.

19. Epler GR. Bronchiolitis obliterans organizing pneumonia. Arch Intern Med 2001;161:158-64.

20. King TE Jr. BOOP: An important cause of migratory pulmonary infiltrates? Eur Respir J 1995;8:193-5.

21. Gross TJ, Chavis AD, Lynch JP III. Noninfectious pulmonary diseases masquerading as community-acquired pneumonia. Clin Chest Med 1991;12:363-93.

22. Corley DE, Winterbauer RH. Collagen vascular diseases. Semin Respir Infect 1995;10:78-85.

23. Strange C, Highland KB. Interstitial lung disease in the patient who has connective tissue disease. Clin Chest Med 2004;25:549-59.

24. Doern GV, Heilmann KP, Huynh HK, Rhomberg PR, Coffman SL, Brueggemann AB. Antimicrobial resistance among clinical isolates of Streptococcus pneumoniae in the United States during 1999-2000, including a comparison of resistance rates since 1994-1995. Antimicrob Agents Chemother 2001;45:1721-9.

25. Doern GV. Antimicrobial use and the emergence of antimicrobial resistance with Streptococcus pneumoniae in the United States. Clin Infect Dis 2001;15:33(Suppl 3):S187-S92.

26. Chen DK, McGeer A, de Azavedo JC, Low DE. Decreased susceptibility of Streptococcus pneumoniae to fluoroquinolones in Canada. Canadian Bacterial Surveillance Network. N Engl J Med 1999;341:233-9.

27. Gotfried MH. Appropriate outpatient macrolide use in community-acquired pneumonia. J Am Acad Nurse Pract 2004;16:146,148,150 (passim). 


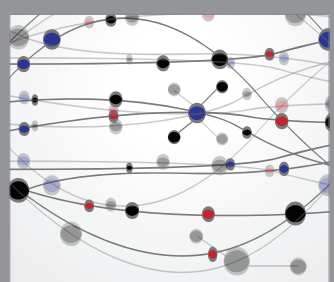

The Scientific World Journal
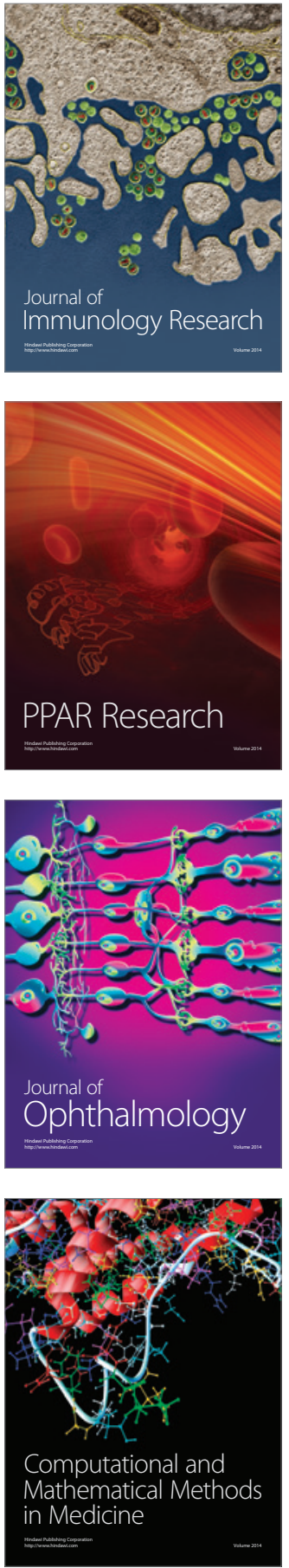

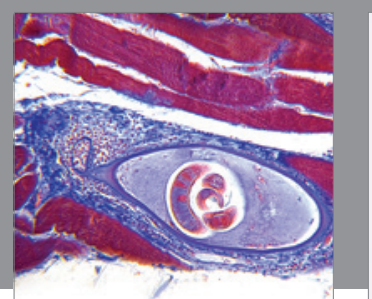

Gastroenterology Research and Practice

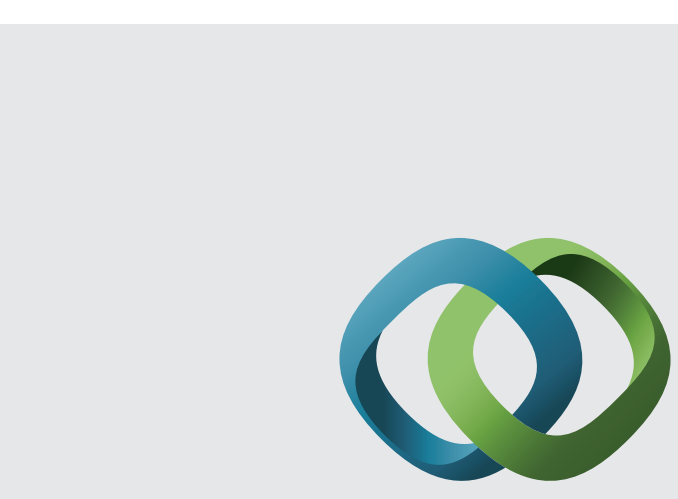

\section{Hindawi}

Submit your manuscripts at

http://www.hindawi.com
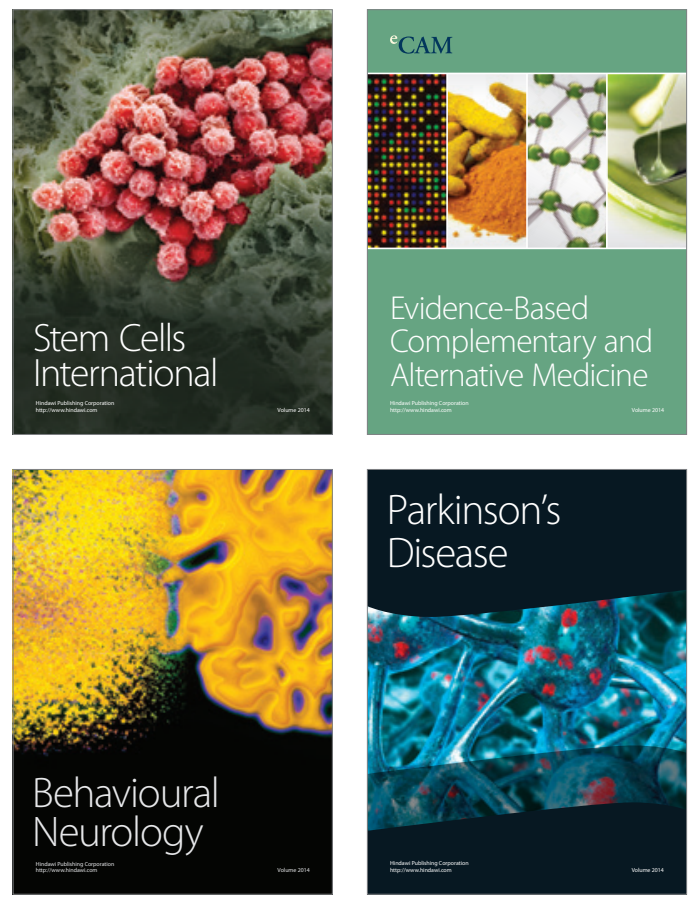
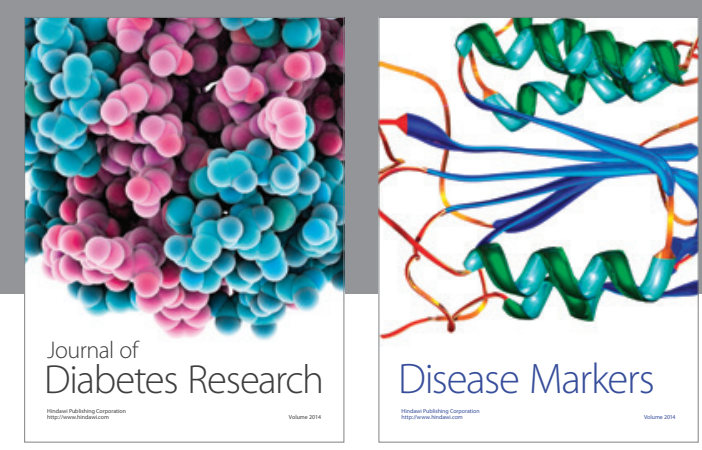

Disease Markers
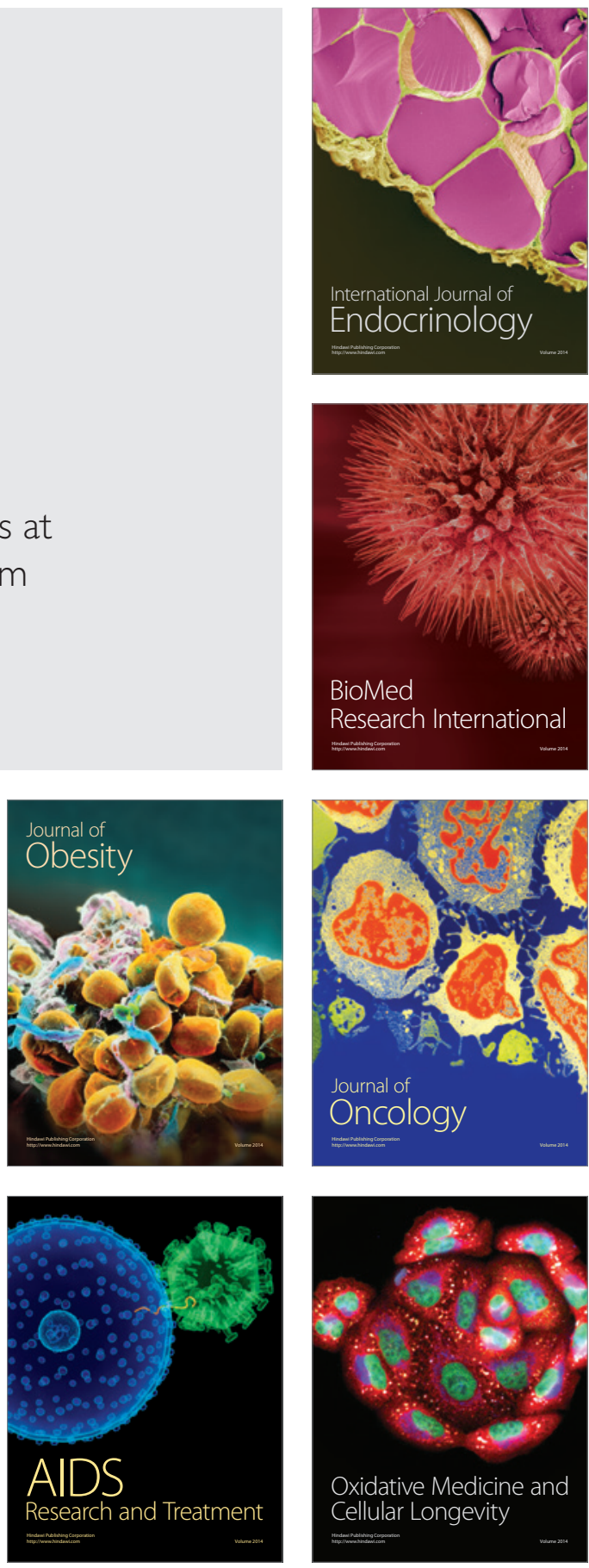